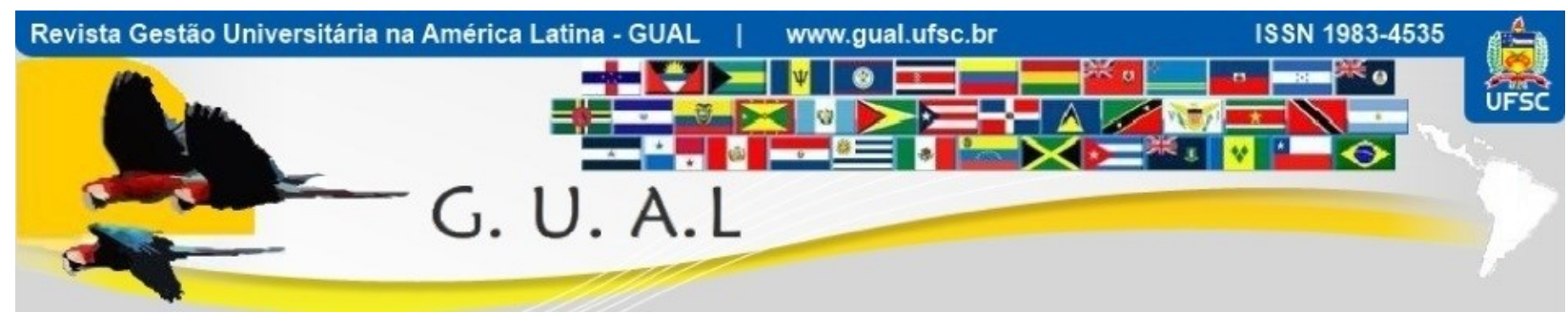

DOI: http://dx.doi.org/10.5007/1983-4535.2017v10n1p17

\title{
KNOWING E SENSEMANKING: CONSTRUÇÃO DE SENTIDO E RENOVAÇÃO DO CONHECIMENTO NO ENSINO À DISTÂNCIA
}

\section{KNOWING AND SENSEMANKING: EVIDENCES IN DISTANCE LEARNING TEACHING ACTIVITY}

Nilson Varella Rübenich, Doutor

Centro Universitário FADERGS nilsonvr@gmail.com

Janine Cardoso Rocha, Mestre Centro Universitário FADERGS janinecrocha@gmail.com

Ana Cristina Fachinelli, Doutora Universidade de Caxias do Sul - UCS afachinelli@gmail.com

Recebido em 09/março/2015

Aprovado em 04/outubro/2016

Sistema de Avaliação: Double Blind Review

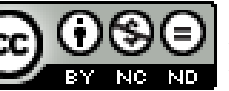

Esta obra está sob uma Licença Creative Commons Atribuição-Uso. 


\title{
RESUMO
}

O conhecimento e sua forma de captação, gestão, criação e desenvolvimento têm despertado a atenção de pesquisadores e organizações, pois se por um lado há uma dependência do conhecimento dos indivíduos que nela atuam, por outro organizações são cada vez mais dependentes do conhecimento dos indivíduos que nela atuam. Neste contexto, o objetivo deste artigo é examinar como o knowing e o sensemaking se manifestam nas atividades de docentes na produção e criação de planos de ensino, conteúdos e atividade de uma Instituição de Ensino Superior - IES - em cursos na modalidade à distância. A pesquisa, estruturada como um estudo de caso, foi realizada com docentes recém-contratados para atuarem no Centro de Educação à Distância - CEAD - de uma IES que faz parte de uma rede de atuação nacional. Para o desenvolvimento deste estudo foram analisados documentos institucionais, realizadas observações diretas com a elaboração de diários de campo e, ao final, questionários abertos foram respondidos pelos docentes envolvidos. Os resultados indicam que o knowing e o sensemaking estão presentes no ambiente que transforma o saber através da ação. A renovação do conhecimento ocorre quando as ações são permeadas por sentidos, em que os saberes possuem significados e são explorados de forma intensa e valorosa.

Palavras-chave: Knowing. Sensemaking. Atividade docente. Educação à distância.

\begin{abstract}
Knowledge and its acquisition, creation and development have awakened the attention of researchers and organizations once there is a knowledge dependence of the individuals that act in the organization. On the other side, organizations are increasingly dependent on the knowledge of the individuals within the organization. In this context this article aims to examine how 'knowing' and 'sensemaking' can be found back in teacher's work when writing course curricula and create lesson plans, as part of the learning content and activities at higher education institutions - HEI - and in distance learning courses. The study was conducted with newly hired teachers working in the Centre of Distance Education - CEAD of a HEI that is part of a nationwide Brazilian educational network. In the development of the case study involved participant observation to elaborate field diaries. Were analyzed institutional documents, and after then was conducted open questionnaires with the teachers involved. The results served as an indication as to what degree the knowing and sensemaking are present in the environment that transforms knowledge into action. The renewal occurs when actions are permeated by senses where knowledge has meanings and is intensively used contributing a profound value added element.
\end{abstract}

Key words: Knowing. Sensemaking. Teaching activity. Distance learning. 


\section{INTRODUÇÃO}

A discussão sobre o conhecimento e sua forma de captação, gestão, criação e desenvolvimento se fundamenta na percepção de que as organizações são dependentes do conhecimento dos indivíduos que nela atuam. Por outro lado, os indivíduos adquirem conhecimentos enquanto permanecem na organização, pois o "conhecimento nasce a partir da experiência, que é um processo subjetivo de percepção, e da apreensão da essência na interpretação do mundo." (NONAKA; TOYAMA; HIRATA, 2010, p. 34). Enquanto bens físicos e materiais se depreciam com o tempo, o conhecimento não perde seu valor, mesmo quando dividido e compartilhado.

Nesse contexto, alguns conceitos começam a se solidificar e relacionam-se estritamente com a construção do conhecimento: o processo de sensemaking e o knowing. Sensemaking, conforme Tillmann e Goddard (2008), é um processo social básico em que os atores sociais buscam entender passado, presente e situações futuras do ambiente organizacional. Os mesmos autores explicam que, neste processo, são considerados tanto os fatores internos quanto os externos. Knowing, a associação dos conhecimentos tácito e explícito com a ação, é o fazer (COOK; BROWN, 1999) e, de acordo com Antonello e Azevedo (2011), não existe distinção entre o pensar e o fazer neste processo, sendo que ele sofre as influências das situações e do contexto onde está inserido.

Neste artigo, propomos uma análise de como novos docentes de uma instituição de ensino superior - IES - que atuam na Educação à Distância - EAD - se familiarizam com as novas propostas pedagógicas. Examinamos o caso dos docentes recentemente contratados, averiguando suas impressões, dificuldades e facilidades quando assumiram a docência de disciplinas na nova instituição. Questionamos: a) que saberes se manifestam e que movimentos são provocados nestes profissionais? b) o que estimula a criação de conhecimentos, em virtude de muitos processos/procedimentos ainda não existirem? c) como conhecer, entender e significar o novo ambiente e propostas da instituição?

O foco da pesquisa se situa no entendimento sobre como esta familiarização aconteceu, quais foram seus facilitadores e dificultadores para que existisse um desenvolvimento orgânico e sustentado. Construimos, neste estudo, o entendimento acerca da utilização dos conhecimentos e significados existentes, tendo como análise as atividades de docentes na produção e na criação de planos de ensino, conteúdos e atividade das disciplinas de cursos na modalidade EAD, buscando relações e contribuições do ambiente para estes 
movimentos. A questão proposta a ser respondida é: como o knowing e o sensemaking se manifestam nas atividades de docentes na produção e criação de planos de ensino, conteúdos e atividade de uma instituição em cursos em EAD?

Além desta introdução, este artigo apresenta, na seção dois, o referencial teórico no qual abordamos os conceitos sobre knowing e sensemaking; na seção três, o método de pesquisa utilizado, detalhando os procedimentos de coleta e análise de dados; na seção quatro, os resultados da pesquisa, estando ela subdividida em subseções que analisam cada fase da pesquisa: a) análise documental; b) observação; c) questionário aberto; na seção cinco, as considerações finais, explorando os resultados obtidos.

\section{REFERENCIAL TEÓRICO}

Muitas pesquisas sobre conhecimento estratégico têm sido realizadas e publicadas na área de gestão, algumas sob o guarda-chuva de 'gestão do conhecimento' (knowledge management) e outras sob o de 'conhecimento organizacional' (organizational knowledge) (VERA; CROSSAN, 2005). O primeiro conceito pode ser definido pelo controle e gerenciamento explícito do conhecimento desejado para que a organização atinja seus resultados. O segundo é menos prescritivo, alterando a noção de conhecimento como uma commodity que organizações e indivíduos podem adquirir, para o de estudo do knowing, como algo que as organizações e indivíduos fazem (VERA; CROSSAN, 2005). Este último conceito discutimos detalhadamente na sequência deste trabalho, por ser o que o mais aderente aos objetivos aqui propostos.

O sensemaking apresenta-se como um olhar para a aprendizagem e a análise organizacional. O sensemaking possui como característica as interações internas do indivíduo que buscam gerenciar e resolver incertezas. Estas interações ocorrem quando novas visões confrontam os significados já elaborados, em um movimento de mudança. Emergem novos insights que ‘aguardam’ nova síntese, novo significado (WEICK, 1995). Este é o processo de sensemaking, conceito que também exploramos neste trabalho.

\subsection{KNOWING}

A alteração da concepção de conhecimento como commodity para knowing é influenciada, em parte, por novas visões que contrapõem fundamentos filosóficos tanto orientais e ocidentais como positivistas e pós-modernos (VERA; CROSSAN, 2005). Nonaka 
e Takeuchi (1997) dividem o conhecimento em dois tipos básicos: tácito e explícito. O conhecimento tácito é pessoal e específico ao contexto, sendo difícil de ser formulado ou comunicado. O conhecimento explícito é transmissível em linguagem formal. $\mathrm{O}$ conhecimento capaz de ser explicitado é muito pequeno frente ao vasto conjunto de conhecimentos existentes. Para a filosofia ocidental, ‘verdadeiro' é o conhecimento explícito, contudo, para a filosofia oriental, é mais valioso o conhecimento tácito.

A noção de conhecimento tácito está ancorada teoricamente em Polanyi (1966), que defende existirem 'coisas' que sabemos, mas não conseguimos contar ou explicar. Este fenômeno ocorre mesmo em algumas situações nas quais se consegue identificar e associar conhecimentos, contudo não se sabe explicar como. Desta forma, o autor propõe o conceito de knowing, que abrange tanto o conhecimento teórico quanto o prático. Este é um conceito importante, pois afirma que o sujeito aprende continuamente a partir da relação de dois eventos, porém, muitas vezes, só consegue entender o todo, sem conseguir identificar estes eventos isoladamente. Vera e Crossan (2005) definem que o knowing não diz respeito a uma possessão, como é o caso do conhecimento, mas a uma prática e à interação com coisas do mundo físico e social. A principal distinção entre conhecimento e knowing é que o primeiro é essencialmente cognitivo, incluindo informações e habilidades possuídas, e o segundo é essencialmente comportamental, o conhecimento como ação.

Buscando elucidar os relacionamentos entre conhecimento, knowing e aprendizagem, Vera e Crossan (2005) afirmam que: a) o conhecimento pode ser obtido pela mente, pela reflexão e pelo corpo (aprender fazendo e aprendizagem experimental); b) o conhecimento pode ser armazenado e acumulado na mente (saber o quê, conhecimento declarado) e nos corpos (saber como, conhecimento procedural); c) knowing é prática, algo que se faz - não é mero conhecimento usado para a prática, é conhecimento como parte da prática; d) aprendizagem é a mudança no conhecimento e a mudança no knowing, o que envolve mudanças cognitivas e comportamentais. Esses relacionamentos estão ilustrados na Figura 1. 


\begin{tabular}{|c|c|c|}
\hline \multicolumn{2}{c|}{ CONHECIMENTO } \\
\cline { 2 - 4 } & Estável & Mudança \\
\cline { 3 - 4 } & Mudável & $\begin{array}{c}\text { Aprendizagem como uma aquisição } \\
\text { de novas informações e/ou } \\
\text { habilidades }\end{array}$ \\
\cline { 2 - 4 } & $\begin{array}{c}\text { Aprendizagem como a prática } \\
\text { de novas informações e/ou } \\
\text { habilidades }\end{array}$ & $\begin{array}{c}\text { Aprendizagem como a aquisição e } \\
\text { prática de novas informações e } \\
\text { habilidades }\end{array}$ \\
\hline
\end{tabular}

Figura 1 Matriz conhecimento-knowing-aprendizagem.

Fonte: Vera e Crossan (2005). Adaptado e traduzido pelos autores.

O conhecimento e o knowing são o conteúdo do processo de aprendizagem, ou seja, o que é aprendido e passa a ser conhecido. De acordo com Antonello e Azevedo (2011, p. 106):

\begin{abstract}
Aprendizagem e conhecimento, denominado 'knowing', são vistos como atividades práticas e realizações: algo que as pessoas 'fazem juntas' (muito mais do que 'pensar sozinho') e que se traduzem como um efeito de acordo e da coordenação coletiva e disposição de diferentes 'materiais' (muito mais do que ‘ideias' ou 'informação').
\end{abstract}

Nonaka e Takeuchi (1997) ressaltam que conhecimento, diferentemente de informação, está relacionado à ação. Conhecimento difere de knowing. Knowing é a ação, é o conhecimento em prática (COOK; BROWN, 1999). Knowing não deve ser confundido com conhecimento tácito, pois este é o conhecimento que se possui mesmo que não esteja sendo utilizado na prática, embora, para que o indivíduo possua o conhecimento tácito, seja necessário ter existido a realização de uma prática anterior.

Para que exista knowing é necessária a participação de pessoas engajadas na criação, no aperfeiçoamento, na utilização e na comunicação do conhecimento (WENGER, 1998). A criação do conhecimento se dá, primordialmente, pela colaboração entre indivíduos (BELLINI; CANONICO, 2008). Estes mesmos autores propõem a questão da necessidade de tensão entre indivíduos, colegas e atividade para o efetivo processo de criação do conhecimento.

Estas tensões ou perturbações mudam a estrutura e as concepções originais do indivíduo. No entanto, para que ocorra esta mudança, o indivíduo deve decidir o que irá perceber e aceitar como perturbação. Esta mudança gera a aprendizagem e o conhecimento por meio de atos cognitivos (CAPRA, 2005). O conhecimento, contudo, não pode ser reduzido a uma atividade cognitiva, pois ele é, antes de tudo, uma atividade social, que reflete 
as influências das situações e não distingue o pensar e o fazer (ANTONELLO; AZEVEDO, 2011). Cardoso e Cardoso (2007) destacam que o conhecimento é adquirido através da experiência e que sua sistematização discursiva é a transformação do conhecimento tácito em explícito.

Nem sempre é possível transmitir o conhecimento tácito previamente existente em conhecimento explícito. Em seu exemplo clássico, Polanyi (1966) descreve o conhecimento tácito, mostrando que, mesmo que uma pessoa conheça outra e a reconheça entre uma multidão, ainda assim ela não conseguirá necessariamente descrever verbalmente como é o rosto desta pessoa, de forma que um terceiro também a reconheça na multidão.

Cardoso e Cardoso (2007) indicam que a dimensão cognitiva do conhecimento tácito define como o indivíduo percebe e se relaciona com os demais e com o mundo, pois está associada a valores, crenças, competências e habilidades do indivíduo. Nesse sentido, a difusão do conhecimento tácito somente pode ser feita pelo contato pessoal, através da observação e da imitação. Os mesmos autores explicam que existe a necessidade de confiança entre os indivíduos da organização e que é requerida a existência de uma linguagem comum entre os membros da organização, porém a transferência de conhecimento somente é possível pelo encontro físico entre estes membros. Stephenson (2011) reitera a necessidade da existência de confiança entre os membros de uma equipe, o que ele considera fundamental. Defende, no entanto, que o conhecimento pode ser gerado e propagado mesmo à distância, desde que exista confiança mútua entre os colaboradores. Caso contrário, estes membros podem até estar juntos, em um escritório físico, e o conhecimento não se gerado.

\subsection{SENSEMAKING}

Weick (1995) define literalmente sensemaking como 'fazer sentido', processo que se dá devido à necessidade de estruturar o desconhecido. Ou seja, quando alguém é posto diante de uma situação ou um evento desconhecido, imediatamente busca organizar esta informação em seu quadro de conhecimentos prévios. Quando estes estímulos são postos dentro do quadro de conhecimentos prévios, que constituem a referência do indivíduo para entender o mundo à sua volta, isso habilita que os novos estímulos sejam compreendidos, entendidos, explicados, atribuídos, extrapolados e preditos (WEICK, 1995).

Como caso extremo de exemplo do sensemaking, Weick (1995) menciona a situação vivenciada por médicos diante da chamada "Síndrome da Criança Espancada", em que, apesar 
das claras evidências para diagnóstico do espancamento, o médico tem uma espécie de 'recusa em ver', negando tal situação (DELUQUI, 1982). Nestes casos, Weick (1995) explica a situação pelo fato de que o evento é tão implausível que médico hesita em reportá-lo por medo de não ser acreditado. Em essência, entende que "isso não pode ser, logo não é" (WEICK, 1995, p. 1). Assim, o processo de sensemaking é complexo, porque vai além de interpretar, pois lida com o desconhecido, com o novo.

O sensemaking, de acordo com Weick (1995), pode ser definido por meio de sete características: processo baseado na construção da identidade; processo retrospectivo; decretado em ambientes sensíveis; social; progressivo; focado em extrair pistas; plausível ao invés de minucioso. Quando as mesmas pessoas interagem dia após dia no mesmo ambiente, é provável que suas atividades sejam mutuamente definidas, dependentes, previsíveis e mais sujeitas ao entendimento comum (WEICK, 1995).

O conceito de sensemaking tem sido ilustrado como a preocupação com a construção e a reconstrução de significado pelas partes envolvidas na mudança. Também se refere à atividade que se preocupa com o processo de fazer sentido na construção de significados para os outros, influenciando as pessoas em direção à situação escolhida pela organização (GIOIA; CHITTIPEDDI, 1991). Para Hasan e Gould (2001, p.78), o sensemaking refere-se a entendimento da situação, estar informado, conhecer para onde a organização está indo e entender a situação. Não se evidencia aprendizagem até que novas ideias se tornem parte do pensamento dos indivíduos e do modo como eles interpretam suas experiências. A aprendizagem acontece quando um novo sentido é formado por meio da reflexão e do compartilhamento das experiências dos indivíduos nas práticas diárias de trabalho, em um processo coletivo e contínuo de interpretação e reinterpretação (REISSNER, 2005).

Reissner (2005), em um contexto de necessidade de adaptação às mudanças constantes, expõe que a aprendizagem é vista como resultado do sensemaking, que seria uma ideia mais ampla do que o desenvolvimento cognitivo, o qual normalmente é o foco das abordagens em aprendizagem. Segundo esta autora, não ocorre aprendizagem a menos que novas ideias se tornem parte do pensamento dos membros da organização e das maneiras como eles interpretam suas experiências. 


\section{MÉTODO DE PESQUISA}

Apresentamos, neste artigo, os resultados de uma pesquisa que teve como objetivo entender a transformação de conhecimentos e significados, tendo como análise as atividades de docentes na produção e na criação de planos de ensino, conteúdos e atividade de cursos em EAD. Para a coleta de dados, utilizamos análise de documentos institucionais, diários de campo de observação direta e, ao final, questionário com perguntas abertas, respondidas pelos docentes. Foram observados os cinco professores do grupo que passou a integrar a equipe, no início de maio de 2013, o quais tinham como missão assumir as primeiras disciplinas da graduação em EAD da IES. Nos primeiros dois dias de atuação na instituição, eles foram submetidos a um treinamento, quando a maioria teve seu primeiro contato com a proposta pedagógica da instituição. Todos eles já tinham experiências em EAD em outras instituições. Isto, por um lado, facilitava a inserção na equipe, por outro, dificultava, pois alguns signos preestabelecidos precisariam ser modificados.

Realizamos inicialmente a análise de documentos institucionais, especialmente da Proposta Pedagógica do CEAD (documento intitulado "Conceitos da Operação Pedagógica"). Esta análise visou compreender as propostas da instituição, o que deveria ser a questão nefrálgica no processo de sensemaking dos pesquisados.

Outra fonte importante de dados foram os diários de campo construídos por dois dos pesquisadores, os quais também atuam profissionalmente no CEAD. Os diários foram construídos durante 4 semanas, entre os dias 22/05/2013 e 19/06/2013. As observações e as anotações foram feitas in loco, no ambiente de trabalho de todos, não havendo qualquer alteração na rotina dos pesquisados devido à presença dos pesquisadores, já que estes estavam em seus postos habituais de trabalho.

Para complementar a coleta de dados, enviamos um questionário aberto com cinco perguntas elaboradas com base no referencial teórico, na análise preliminar das observações realizadas e em documentos institucionais. Optamos por coletar dados por questionário ao invés de entrevista por entender que os pesquisados assim se sentiriam mais à vontade em responder, uma vez que nós, pesquisadores, éramos seus colegas de trabalho, existindo inclusive relação de subordinação entre alguns. Desta forma, encaminhamos o questionário por e-mail aos cinco professores recentemente contratados. Destes, quatro responderam o questionário, colocando-se à disposição para responder questões adicionais que surgissem a partir de suas respostas. Além das perguntas iniciais, foram feitos questionamentos adicionais 
para dois respondentes via e-mail, com o objetivo de esclarecer algumas respostas que não haviam ficado claras. Estes questionamentos foram prontamente respondidos.

As respostas dos questionários foram codificadas como R1, R2, R3 e R4. Por ser um grupo muito reduzido, optamos por não informar características individuais para preservar o anonimato de seus componentes. Os respondentes pertencem aos sexos masculino e feminino, estão na faixa etária entre 30 e 40 anos, são graduados e pós-graduados (stricto sensu) em suas áreas de atuação. A formação mínima é mestrado e a máxima, doutorado.

A análise dos dados foi efetivada através do método de análise de conteúdo, com adoção da técnica de codificação/categorização aberta (STRAUS; CORBIN, 2008). Esta opção foi feita a fim de não 'contaminar' a leitura inicial com categorias previamente definidas, buscando encontrar o que emergiu livremente, sem as 'amarras' de categorias apresentadas pela literatura revisada ou de ideias prévias dos pesquisadores.

\section{RESULTADOS DA PESQUISA}

A pesquisa foi realizada na unidade de EAD de uma rede de ensino de abrangência nacional, presente nas cinco regiões brasileiras, com mais de 100 unidades de Educação Básica e 20 unidades de Ensino Superior. A instituição foi fundada, na década de 1940, com o ideal de levar educação para localidades e populações não atendidas pelo ensino público, realidade de muitas comunidades até há pouco mais de uma década.

Em meados de 2010, por demanda da mantenedora, foi escolhida umas das IES mantidas com objetivo de criar e executar um projeto de EAD próprio para toda a rede. Naquele momento, a unidade escolhida oferecia uma série de atributos que a habilitaram, destacando-se os recursos humanos capacitados e com experiência em EAD e os recursos financeiros equilibrados que permitiam investimentos em infraestrutura, pesquisa e desenvolvimento.

Em cerca de três anos de história, o que era um pequeno núcleo dentro da IES transformou-se em uma Centro de Educação à Distância - CEAD - que presta efetivos 'serviços' de EAD para a rede. Estão em funcionamento quatro cursos de graduação, com 34 (trinta e quatro) polos espalhados de norte a sul do Brasil, todos em unidades da própria rede. Em meados de 2013, os cursos de graduação estavam com cerca de 700 alunos, todos ingressantes no primeiro processo seletivo. Além disso, encontrava-se em fase adiantada a primeira turma de um curso de MBA, realizado in company sob encomenda da mantenedora, 
o qual tem como alunos cerca de 470 lideranças das mais de 120 unidades da rede (diretores, coordenadores etc.). Também estavam em fase de lançamento cinco novas turmas de especialização, sendo uma in company e quatro abertas ao público em geral.

Nesta mesma época a estrutura do CEAD contava com uma equipe dedicada de 25 profissionais dentre coordenadores, professores, tutores e técnicos administrativos, além de 20 professores colaboradores eventuais. Os serviços de secretaria, tecnologia da informação, financeiros e administrativos em geral eram prestados por outras áreas da IES.

O presente estudo foi desenvolvido neste ambiente, por tratar-se de um caso particularmente interessante, devido ao fato de ser uma unidade de EAD em formação. Este processo estimulou a criação de conhecimentos, uma vez que muitos processos ainda não existiam. Mostrava-se também um ambiente interessante por possuir uma postura de gestão questionadora, que estimulava a pensar os fazeres de forma diferente (um questionamento bastante presente a todos os profissionais que atuam nesta unidade é: 'por que não de outra forma?'), tornando-se um ambiente propício à constante construção de significados e à transformação de conhecimentos. Além disso, possuía em sua equipe profissionais contratados recentemente que precisavam conhecer, entender e significar o novo ambiente e as propostas educacionais da instituição e, em especial, do CEAD.

A seguir, apresentamos os dados e as análises em três momentos, organizados em três subseções. A primeira subseção apresenta a análise documental, sendo centrais os 'pilares' da 'operação pedagógica', norteadores do pensamento institucional no CEAD. A segunda subseção apresenta os resultados das observações realizadas in loco, com análise dos diários de campo. A terceira subseção contém a análise dos dados obtidos nos questionários abertos respondidos pelos professores pesquisados.

\subsection{ANÁLISE DOCUMENTAL}

O documento "Conceitos da Operação Pedagógica" foi elaborado pela Equipe Multidisciplinar do CEAD, no intuito de guiar ações e práticas nos cursos oferecidos pela instituição em diferentes níveis. Alimentando-se do Projeto Pedagógico Institucional (PPI) e do pensamento contemporâneo pós-moderno em educação, o documento inicia analisando e refletindo sobre o atravessamento das tecnologias da informação e da telecomunicação nos modos de pensar, aprender e conhecer, que "instalam, para o ensino presencial e para o ensino à distância, a necessidade de ações interativas que visam à iniciativa, à flexibilidade e à 
autonomia no processo de formação, dimensões estas que expressam rupturas de cunho epistemológico e pedagógico aos modelos de ensino centrados no professor e na transmissão de conteúdos" (CEAD, 2012, p. 4).

O documento ressalta a necessidade da constituição de um sistema de comunicação que possibilite a construção coletiva e criativa de conhecimento. Estabelece fios condutores para as relações entre professores e equipes de curso e destes com os alunos: a) ética; b) problematização; c) ressignificação; d) interatividade; e) autonomia; f) hipertextualidade.

Sobre a ética, o documento destaca que "o posicionamento ético implica responsabilizar-se com modos diferentes de existir" (CEAD, 2012, p. 7), pautado pelo acolhimento e pela promoção de bons encontros nas relações, por compreender que o ser humano é um ser incompleto, em permanente formação.

A problematização se constrói pelo entendimento de que o conhecimento advém da interação do sujeito com a cultura, sendo fundamental a atuação do próprio aluno na elaboração de significados para os conteúdos no espaço de sua profissão, construindo competências para a futura atuação profissional. Fundamenta-se na certeza de que a produção de significados está intimamente ligada ao olhar do indivíduo sobre o mundo, à maneira como este é problematizado e às possibilidades de estranhamento da vida cotidiana. Dito isto, a problematização torna-se forma de provocar reflexão, buscando alternativas àquilo que desassossega. Assim, o ato de questionar torna-se mais importante do que o ato de responder, já que coloca em movimento novas possibilidades de interpretação, desnaturalizando certezas e respostas prontas. O questionamento do "porquê dessa maneira e não de outra que tais acontecimentos e verdades se instituem" (FOUCAULT, 1994) é complementado pela ideia de que "...nada aprendemos com aquele que nos diz: faça como eu. Nossos únicos mestres são aqueles que nos dizem 'faça comigo' e que, em vez de nos propor gestos a serem reproduzidos, sabem emitir signos a serem desenvolvidos no heterogêneo" (DELEUZE, 1988, p. 54, CEAD, 2012 p. 9-10), tornando imprescindível o ato de problematizar, induzindo o aprendente pela provocação do pensamento, o que gera rearranjos. A problematização deve ser expressa, então, por 'disparadores', presentes em cada unidade de estudo, de forma que sejam capazes de mobilizar formas de pensar.

A ressignificação está fundamentada em Hengemühle (2010), que defende:

ser fundamental que o professor conheça profundamente os conteúdos que vai trabalhar, investigue as teorias, suas construções e modificações, identificando sua origem (fatos, situações e problemas). A partir destas informações, estabeleça 
conexões de acordo com o contexto sociocultural dos alunos, do que lhes é significativo, possibilitando assim, a construção de sentido para o novo conhecimento teórico a ser abordado, ressignificando assim os conceitos de acordo com os problemas do presente (HENGEMÜHLE, 2010).

A autonomia é entendida como meio para que o aluno seja sujeito de sua própria aprendizagem, desenvolvendo espírito crítico, através de debates, diálogos, encontros e experimentações de novos modos de estar no mundo, promovendo resistências aos modos de ser que impedem a potência do pensamento e da vida (CEAD, 2012, p. 13). Para isto, o documento defende a necessidade da promoção da interatividade e da cooperação. A primeira é potencializada pelas vias de comunicação, com a participação dos atores que devem estar dispostos a se exporem no grupo, propondo questões, problemas ou ideias que abrem as zonas de acionamento para questões até então inusitadas aos demais atores, podendo ser geradores de aprendizagens não previstas e variadas.

A hipertextualidade aparece como modo de romper com as formas lineares e segmentadas de organização de conteúdos e construção do conhecimento. Para isso, contrapõe a visão tradicional da 'árvore do conhecimento' com a metáfora do rizoma, ideia defendida por Deleuze e Guattari (1996). Estes autores argumentam que a construção do saber tem forma múltipla, "uma vez que as pequenas raízes mostram-se emaranhadas, com linhas que se entrelaçam, permitindo pensar os saberes como um conjunto complexo, entrecruzado em múltiplas formas e relações" (DELEUZE; GUATTARI, 1996, CEAD, 2012). Em complemento, o documento busca em Levy (1999) sustentação para afirmar que o hipertexto é como o rizoma. Assim, a hipertextualidade, utilizando a potência da internet com suas diferentes mídias, propicia ao aluno/navegador a possibilidade de se conectar ao conhecimento de diferentes pontos, conforme sua bagagem e seu sentido, o instigando a criar caminhos próprios. Esta ideia é ilustrada por um trecho de um poema do espanhol Antônio Machado: “caminhante, não há caminho, o caminho se faz ao caminhar". Estas ideias vão ao encontro daquelas de Deleuze e Guattari (1996), os quais argumentam que o conhecimento tem mais a forma de um rizoma do que de uma árvore, pois, em sua visão, o conhecimento das diversas áreas disciplinares se entrelaça, formando um conjunto complexo, no qual os elementos se remetem uns aos outros e, muitas vezes, para fora do próprio conjunto, permitindo novas conexões e entradas não hierarquizadas. 


\subsection{OBSERVAÇÃO}

Desenvolvemos esta atividade no período de 22/05/2013 a 19/06/2013. Identificamos alguns 'movimentos' na adaptação do novo corpo docente ao ambiente. O corpo docente em questão é composto por cinco professores recentemente contratados como professores de disciplina, quatro deles em regime de tempo integral e um em tempo parcial. Compete a estes profissionais desenvolver materiais, com base em livros digitais previamente criados por professores conteudistas, associando estes livros digitais a materiais multimidiáticos, como vídeos, artigos, figuras, além da criação e do desenvolvimento de materiais de autoria própria, especialmente textos e vídeos.

O ambiente do CEAD é composto por 'ilhas' de trabalho, mesas hexagonais que acomodam seis estações de trabalho cada. Cada ilha abriga uma área do conhecimento, tendo a 'ilha' da Gestão, a 'ilha' da Pedagogia e a 'ilha' da Teologia. Foram disponibilizados recursos para o trabalho confortável da equipe: computadores com telas de 22 polegadas, fones de ouvido com abafador de ruídos, climatização, cadeiras giratórias estofadas, teclados e mouses ergonômicos. Existe, no entanto, proximidade entre os postos de trabalho, com pouco espaço livre nas mesas para consultar materiais como livros, por exemplo. A proximidade torna qualquer conversa ruidosa, dificultando a concentração. Por isto, é estimulado o uso de fones de ouvido e a comunicação escrita por skype, um software que possibilita a realização de conversas através de mensagens de texto ou voz via web.

Durante o mês em que foi realizada a observação, identificamos aproximações e distanciamentos entre as pessoas. No primeiro momento, houve aproximação, buscando a discussão sobre os conteúdos previstos no projeto pedagógico dos cursos e sobre a proposta pedagógica da instituição. Essas discussões se desenvolveram de forma mais intensa entre os professores dentro de seus cursos, tendo eles recorrido constantemente às respectivas coordenações. De forma menos intensa, notamos trocas entre professores de cursos diferentes. Nos dois cursos da área de gestão, agrupados na mesma ilha, sob a mesma coordenação e com disciplinas comuns, percebemos que curiosamente um dos professores se identificou e 'adotou' um dos cursos, enquanto o outro teve processo semelhante com o outro curso. Essa aproximação pode ser reflexo da formação de cada um dos docentes, já que o professor com formação e trajetória profissional na área de Recursos Humanos identificou-se mais com o curso de Tecnologia em Gestão de Recursos Humanos e o professor com formação em Sistemas de Informação, com o curso de Tecnologia em Processos Gerenciais. Foi necessária 
uma conversa do coordenador dos cursos com os docentes para esclarecer que ambos eram professores dos dois cursos.

No segundo momento, notamos distanciamento um pouco maior entre os professores, que começaram a trabalhar de forma mais intensa no desenvolvimento de suas disciplinas. Neste processo, chamou nossa atenção o fato de um dos professores ter optado em ficar em uma mesa distanciada. Este movimento pareceu-nos, em primeira instância, de segregação, contudo rapidamente identificamos que o distanciamento tinha o propósito de evitar o barulho proveniente das conversas paralelas e de ter maior espaço para disposição dos diversos materiais, especialmente livros e dispositivos eletrônicos com os quais ele trabalhava e que não cabiam na mesa de sua estação de trabalho na ilha.

Identificamos também a dificuldade que os professores sentem ao terem que cumprir horários previamente estabelecidos. Em respeito à legislação trabalhista e evitando futuras demandas judiciais, a IES estabelece horários fixos de trabalho, em jornadas de, no máximo, 8 horas diárias, com intervalo de uma hora ou em turnos de, no máximo, 6 horas. Esse sistema de trabalho com horários definidos é diferente do que os professores estavam acostumados. Alguns comentaram sobre a dificuldade que tinham de realizar, em horários rígidos, o trabalho de desenvolvimento de conteúdos que requer criatividade. Um dos professores relatou que estava acostumado a trabalhar durante a madrugada e depois dormir até tarde. Explanou que no horário noturno produzia melhor, estando, pois, com dificuldades para desenvolver trabalho de criação no período da manhã, quando se sentia cansado e com sono.

\subsection{QUESTIONÁRIO ABERTO}

$\mathrm{Na}$ primeira pergunta, foi questionado como o respondente havia tomado conhecimento da proposta pedagógica do CEAD. Esta pergunta obteve respostas bastante diversas. Dois respondentes (R1 e R2) destacaram que tiveram o primeiro contato com a proposta durante o treinamento realizado nos primeiros dias. Uma das respostas, bastante detalhada (R2), evidenciou um dado interessante: um dos fatores que fez com que R2 decidisse assumir o cargo foi a certeza dada, no processo seletivo, de que haveria interação com o discente, algo para ele fundamental na prática de EAD e que, em algumas instituições pelas quais havia passado, não acontecia.

O segundo questionamento abordava o que chamou mais havia chamado a atenção na proposta pedagógica da instituição. Os novos docentes foram unânimes em destacar a lógica 
rizomática, que refuta a ideia da árvore do conhecimento, acreditando que o conhecimento não tem início, meio ou fim, sendo construído e reconstruído por diversos ângulos e lógicas, percorrido através de encontros e desencontros. Esta proposta mostrou-se uma novidade, visto que alguns docentes nunca haviam atuado com esta forma de construção do conhecimento. Os docentes destacaram que tal proposta educativa é enriquecedora, na medida em que propõe ao discente inúmeras possibilidades de construção do saber, isto é, o aluno é quem decide por qual caminho seguirá, sendo todas as disciplinas 'cruzadas' por eixos transversais. Os respondentes ressaltaram, contudo, que assim como ela se apresenta como um elemento surpreendente, torna-se também desafiadora, por ser necessário construir conteúdos que respeitem esta lógica, sem contar com possíveis conhecimentos prévios dos alunos, supostamente 'recebidos' em disciplinas anteriormente cursadas. Outros diferenciadores mencionados por um dos docentes (R1) são a utilização de 'disparadores' no início de cada conteúdo e a forma de acolhimento proporcionada ao aluno. Ele destaca estes dois aspectos, alinhados à questão rizomática, como cruciais para o sucesso do curso e a consecução da proposta pedagógica.

Quando questionados sobre o quanto esta proposta os aproximava das práticas docentes anteriores com as quais já estavam familiarizados, somente um dos docentes (R2) mencionou uma aproximação possível. Ele se referiu às ferramentas de interação com os alunos, informando que em outras instituições em que atuou também eram utilizadas ferramentas de chat e fóruns. Ele, no entanto, entende que a forma de uso é diferenciada nesta EAD, já que, na instituição anterior, a interação ocorria quase exclusivamente entre tutores e alunos, não acontecendo nunca entre professor e aluno. O professor limitava-se a elaborar o plano de ensino e a produzir o conteúdo, ficando o contato com o corpo discente distante, quase inexistente.

Outros distanciamentos foram destacados das práticas anteriores. Cada um dos respondentes apresentou um aspecto que chamava sua atenção nestes distanciamentos. Um dos docentes (R3) enfocou a concepção rizomática do currículo, algo totalmente novo para ele. Outro (R4) falou sobre a hipertextualidade, já que esta evoca o distanciamento da 'educação bancária' (referindo-se ao conceito de Paulo Freire). Outras propostas de EAD adotam material apostilado, repleto de longos textos, e vídeos que expõem o conteúdo com pouquíssima interação com o discente tanto em relação ao conteúdo quanto aos conhecimentos com pontos de vista diversos e críticos, havendo complementação em 
encontros presenciais de reforço do exposto nas cartilhas. Foram igualmente abordados tanto o acolhimento e a utilização de disparadores que, na visão de R1 e R2, instigam o aluno a buscar caminhos para construírem o conhecimento, como a utilização de elementos hipertextuais que agregam saber.

Colocar a proposta pedagógica do CEAD em prática tem sido um desafio para os docentes, por motivos diversos. Para um deles (R2), apresenta-se como dificuldade a questão tecnológica, visto ser o próprio docente quem 'alimenta' a plataforma virtual. Este mesmo docente traz à tona a questão da escassez de tempo, pois o modelo rizomático e a utilização de elementos hipertextuais demandam maior dedicação à pesquisa e maior cuidado na utilização de imagens e materiais de terceiros. Para outro docente (R1), a principal dificuldade firma-se em uma questão administrativa, visto que o corpo docente necessita cumprir uma carga horária previamente estabelecida e inflexível. Isto, na percepção deste docente, dificulta a construção dos materiais em momentos de maior 'inspiração'. Outro professor (R4) refere a questão rizomática, contudo sob a ótica do discente e a importância de se preparar o aluno para esta proposta tão diferenciada. Este tópico é corroborado por outro professor (R3), que demonstra preocupação com o cursista do EAD e sua preparação para interagir com esta proposta tão desafiadora e as questões mais tecnológicas. Conforme este docente, muitos alunos têm dificuldade com o ambiente virtual e isso requer atenção e cuidado.

Quanto aos facilitadores de sua inserção na instituição e na apropriação da proposta pedagógica, dois dos professores (R1 e R2) destacam que ter uma equipe multidisciplinar apoiando o corpo docente facilita para que a proposta pedagógica seja posta em prática. A equipe de apoio e suporte é classificada como facilitadora e de 'excelente qualidade' (R1). Foram destacados, como de grande valia, aspectos como união do grupo, alinhamento da equipe à proposta, orientação da coordenação geral do CEAD. Foi ressaltada por R2 a liberdade dada ao docente para o planejamento da disciplina e a elaboração de materiais, o deixando confiante e seguro para fazer suas escolhas.

A última questão explorava a 'transformação' do docente tendo como base seus conhecimentos prévios. Um dos professores (R2) relatou que a proposta rizomática, tão estimulada no CEAD, está sendo inspiradora, de certa forma, para suas aulas presenciais. Destaca que o fato de 'pensar' em todas as aulas, antes mesmo delas ocorrerem, característica da EAD, está proporcionando seu amadurecimento nas formas de trabalhar também na modalidade presencial. Outro respondente (R1) assinalou a importância desta forma de ensino 
para a sociedade contemporânea, no que tange um ensino voltado ao desenvolvimento, ao ser colaborativo, ao não linear, à interatividade. Um terceiro ponto de vista (R4) foi a questão da forma de comunicar os saberes, no modo de transmitir o conhecimento, na busca da sinteticidade, na comunicação clara e objetiva, fácil de ser entendida nos diferentes lugares nos quais está acessível a educação na modalidade EAD, com utilização de diferentes mídias. O respondente relata ter se dado conta que a forma também comunica, "não se trata apenas de uma questão estética" (R4) e que a forma de dispor os conteúdos aos alunos proposta pelo CEAD tem transformado sua visão e sua ação docente. Por último, houve o relato de um dos professores (R3) de que sua transformação iniciou-se no momento em que passou a integrar a equipe do CEAD. Relata ter percebido, desde este momento, que o que transforma são a “intenção e intensidade". Ele sente que estes elementos estão presentes e atuantes no grupo de trabalho do CEAD. Nas palavras de R3: “conhecimentos prévios são tecnológicos e teóricos, são como sementes que só tornam-se férteis se cultivadas na intencionalidade".

Pelos depoimentos, observam-se presentes, neste ambiente, os fenômenos do knowing e do sensemaking. Ele é um ambiente que transforma o saber através da ação e esta se renova e muda a cada instante, todas as ações são permeadas por sentidos, isto é, os saberes possuem significados e são explorados em sua prática de forma intensa e valorosa. Notamos o esforço dos docentes em não apenas 'adquirir' novos conhecimentos e ideias propostas pela instituição onde passaram a trabalhar, nem tampouco colocar em prática conhecimentos prévios em nova forma de operação, mas também em provocar um constante movimento de aquisição e prática de novas informações e habilidades. Esse movimento se evidencia no planejamento das aulas, na construção de conteúdos, na interação com novas tecnologias, em novas formas de organização do trabalho e do espaço. As 'novidades' tanto da operação pedagógica como do próprio jeito de fazer e pensar as atividades de diárias permeiam a ação e a busca, alterando os sentidos e os significados dos docentes, que se mostram engajados na construção e na solidificação da proposta.

\section{CONSIDERAÇÕES FINAIS}

Uma proposta diferenciada como a preconizada pelo CEAD tem sabores e dissabores, é permeada por desafios e por situações problemáticas. Por ser uma proposta que propõe o pensamento diferente e desterritorializante pode, eventualmente, desestabilizar. Contudo, verificamos, nas observações e nas respostas, que, embora existissem o receio e a expectativa 
do novo, também havia a tranquilidade de poder contar com o apoio da equipe multidisciplinar e coordenação geral do CEAD, formada por pessoas que conhecem e estão alinhadas à proposta pedagógica. Esse suporte se manifestou na percepção e no sentimento dos docentes de serem integrantes de um grupo unido, que se apoia e se sustenta.

O knowing e o sensemaking se manifestam tanto neste ambiente, como nas atividades dos docentes. Conforme Wenger (1998) explicita, a participação de pessoas engajadas na criação, no aperfeiçoamento, na utilização e na comunicação do conhecimento é fundamental para que exista knowing. Esse engajamento estava presente no CEAD. Ele se evidenciou quando, nas observações realizadas, percebemos que os professores, embora sinalizassem e reconhecessem a dificuldade em explorar seu lado criativo em horários previamente estabelecidos, buscavam formas inventivas de adaptação, em um claro entendimento das necessidades da instituição. A comunicação e a utilização do conhecimento se explicitaram nas discussões e nas trocas, trazendo novas aplicações, novas possibilidades e novos saberes. Identificamos o sensemaking quando se manifestaram a construção e a desconstrução dos saberes previamente existentes. Quando confrontamos as aproximações e os distanciamentos das práticas anteriores dos docentes, notamos que houve adaptação e entendimento de que, neste espaço, as situações, mesmo quando similares, se distanciavam, de alguma forma, daquilo que eles já conheciam e já haviam experienciado. Esse achado vai ao encontro do explanado por Gioia e Chittipeddi (1991), Weick (1995) e Reissner (2005), ao dizerem que o processo de formulação de novos sentidos, de novos significados é resultante do processo de sensemaking.

Alguns saberes se manifestaram na forma de transmissão do conhecimento, conforme evidenciado nas respostas dadas pelos pesquisados. Talvez ainda mais importante seja que esta forma de pensar e trocar conhecimento está ultrapassando os limites do CEAD, sendo explorada em outras oportunidades vislumbradas como possíveis pelos docentes, por exemplo, nas aulas na modalidade presencial. Estes professores estão sendo provocados a pensarem uma nova forma de ensinar para uma nova forma de aprender, com foco no desenvolvimento, na colaboração, na interatividade. Estes profissionais estão sendo instigados à comunicação mais clara, focada e objetiva, de fácil entendimento, mais acessível. Estes achados estão alinhados ao que se preconiza na análise documental realizada, que traz os seis “fios condutores" da proposta pedagógica do CEAD (ética, problematização, ressignificação, interatividade, autonomia, hipertextualidade). 
Entendemos, pela análise dos dados, que justamente em virtude de muitos processos/procedimentos ainda não existirem no CEAD esse estava sendo um estimulador da criação de conhecimentos. Alguns professores mencionaram que a liberdade dada ao docente para criar, planejar a disciplina, elaborar materiais lhes proporciona confiança e segurança ao fazerem suas escolhas. Paradoxalmente a esta liberdade, há a preocupação com o tempo necessário para a construção de materiais que reflitam a proposta rizomática (a qual preconiza que o conhecimento não tem início, não tem meio e não tem fim), principal diferenciador da proposta pedagógica do CEAD. Os docentes estavam cientes e crentes da importância da hipertextualidade, da utilização de recursos multimidiáticos e da elaboração de conteúdos atraentes e envolventes aos seus discentes. Sentiam-se, entretanto, conflitados com a escassez de tempo para elaboração de conteúdos, a busca de elementos externos, os cuidados com direitos autorais, o domínio do ferramental tecnológico, entre outros. Estas questões emergiram nesta nova proposta e, de forma geral, ainda não tinham sido experienciadas por estes docentes. Ainda assim, percebemos que a vontade de fazer diferente, de criar e de se envolver nesta proposta tão exclusiva estimulava os docentes a ponto de eles se mostrarem confiantes e crédulos na possibilidade de construção de uma nova forma de saber.

A resposta de um dos docentes (R3), ao ser questionado sobre a 'transformação' de seus conhecimentos prévios, foi que "conhecimentos prévios são tecnológicos e teóricos, são como sementes que só tornam-se férteis se cultivadas na intencionalidade". Esta afirmação reflete como estes profissionais passaram a conhecer, entender e significar o novo ambiente e as propostas desta nova instituição: um semear contínuo de rizomas que constroem saber de forma múltipla, que se entrelaçam simultaneamente na complexidade e na simplicidade, em que as conexões acontecem e se multiplicam. Um espaço onde o aprender caminha junto com o desaprender, criando novos sentidos, conhecimentos e desconhecimentos, fundamentais para a criação e a disseminação do conhecimento.

\section{REFERÊNCIAS}

ANTONELLO, C. S.; AZEVEDO, D. Aprendizagem Organizacional: explorando o terreno das teorias culturais e das teorias baseadas em práticas. In: ANTONELLO, C. S.; et. al. Aprendizagem Organizacional no Brasil. Porto Alegre: Bookman, 2011, p. 89-113.

BELLINI, E; CANONICO, P. Knowing communities in project driven organizations: Analysing the strategic impact of socially constructed HRM practices. International Journal of Project Management, 2008. 
CAPRA, F. As conexões ocultas: ciência para uma vida sustentável. Tradução: Marcelo Brandão Cipolla. São Paulo: Cultrix, 2005.

CARDOSO, L; CARDOSO, P. Para uma revisão da teoria do conhecimento de Michael Polanyi. Revista Portuguesa de Pedagogia, 2007.

CEAD - Centro de Educação à Distância. Proposta Pedagógica. Osório: CNEC, 2012

COOK, S.D.N.; BROWN, J.S. Bridging Epistemologies: The Generative Dance between Organizational Knowledge and Organizational Knowing. Organization Science, 1999.

DELEUZE, G. Diferença e repetição. Rio de Janeiro: Graal, 1988.

DELEUZE, G.; GUATTARI, F. Mil platôs: capitalismo e esquizofrenia. Vol. 1. São Paulo: Ed. 34, 1996.

DELUQUI, C. G. A síndrome da criança espancada. Pediatria, São Paulo, p. 26-34, 1982.

FOUCAULT, Michel. Dits e écrits. Paris: Gallimart,1994.

GIOIA, D. A.; CHITTIPEDDI, K. Sensemaking and Sensegiving in Strategic Change Initiation. Strategic Management Journal, v. 12, p. 433-448, 1991.

HASAN, H., GOULD, E. Support for the sense-making activity of managers. Decision Support Syst. V. 31, p. 71-86, 2001.

HENGEMÜHLE, A. Gestão de Ensino e Práticas Pedagógicas. São Paulo: Vozes, 2010.

LEVY, Pierre. Cibercultura. São Paulo: Ed. 34, 1999.

NONAKA, I.; TAKEUCHI, H. A criação do conhecimento na empresa. Rio de Janeiro: Elsevier, 1997.

NONAKA, I.; TOYAMA, R.; HIRATA, T. Teoria e Casos de Empresas Baseadas No Conhecimento - Managing Flow. Bookman, 2010.

POLANYI, M. The Tacit Dimension. New York: Soubleday\&Company, 1966.

REISSNER, S. C. Learning and innovation: a narrative analysis. Journal of Organizational Change Management, v. 18, p. 482-494, 2005.

STEPHENSON, K. From Tiananmen to Tahrir: Knowing one's place in the 21 st century. Organizational Dynamics, v. 40, p. 281-291, 2011.

STRAUSS, A.; CORBIN, J. Pesquisa qualitativa: técnicas e procedimentos para o desenvolvimento de teoria fundamentada. $2^{\circ}$ ed. - Porto Alegre: Artmed, 2008. 
TILLMANN, K.; GODDARD, A. Strategic management accounting and sense-making in a multinational company. Management Accounting Research, 2008.

VERA, D.; CROSSAN, M. Organizational Learning and Knowledge Management: Toward an Integrative Framework. in.: EASTERBY-SMITH; Mark; LYLES, Marjorie A. (Eds.). Handbook of Organizational Learning and Knowledge Management. Blackwell Publishing, 2005.

WENGER, E. Learning as a Social System. Systems Thinker, 1998.

WEICK, K.E. Sensemaking in Organizations. London: Sage Publications, 1995. 